

\section{TOWARDS \\ A GENDER-SENSITIVE PRIVATE SECTOR IN THE OPT}

\section{ASMAA ABUMEZIED and RAHHAL RAHHAL}

This learning paper sums up the experience of conducting a Participatory Gender Audit with private sector companies in the agriculture sector in the OPT. The paper defines the approach used, and provides insights into the main findings, learning, and challenges faced during implementation. Generally speaking, issues such as women's limited access to the labor market, weak representation both as staff and as decision makers, the absence of gendersensitive working conditions and policies in place, and the lack of consideration for women as customers and suppliers, are among the main issues highlighted. 


\section{O1 INTRODUCTION}

Over the past decades, significant efforts have been made to address the systematic gender inequalities facing Palestinian women from a legislative, social and political standpoint. Though supporting women's economic empowerment has focused on female integration into the labor market, in recent years, supporting women's businesses and women up-skilling - a fundamental partnership with the private sector as an actor to support gender equality - has become inevitable. This necessitates a holistic approach to women's economic empowerment based on the premise of investing in women as a strategic objective for improving the economy.

A closer look at the status of women in the agriculture sector shows how badly affected women have been. For example, female participation in agricultural activities has dropped from 36 percent to 6.8 percent in a decade, while male participation in the agricultural labor force neared 6.2 percent in 2018, a drop from 11 percent in 2007. Female workers have been profoundly stricken by this drop .

Furthermore, women are predominantly concentrated as unpaid family laborers (76 percent in 20182) and in the informal food processing sector at the household level. Their participation at the food industry levels follows the overall trend of weak women participation in the labor market. 
A fundamental premise underlying Oxfam's economic justice work is the mainstreaming of gender equity principles at the macro and micro levels in the economic sector to ensure a sustainable change. Oxfam built on the findings of the "Making Markets Work for Women" study of 2016 to guide its efforts in supporting a more gender-inclusive private agricultural sector. The initiatives Oxfam started then primarily focused on a more gender-sensitive work environment through investing in infrastructure that considers and adapts to women's needs. The subsequent years necessitated a more holistic view at the company level to go beyond adapting the environment to changes at the companies' structural levels such as representation, guidelines, and manuals. Therefore, Oxfam commissioned the ILO Participatory Gender Audit process in 2019-2018 on several companies in the OPT to help enhance gender institutionalization in their policies, services and products, budgets, and structures.

\section{What is A Participatory Gender Audit?}

A tool and a process based on a participatory methodology. It promotes organizational learning on mainstreaming gender practically and effectively. It considers whether internal practices and related support systems for gender mainstreaming are effective and reinforce each other and whether they are being followed. It establishes a baseline; identifies critical gaps and challenges; and recommends ways of addressing them, suggesting possible improvements and innovations. It also documents good practices towards the achievement of gender equality.

This paper sums up 0xfam's experience concerning the use of the gender audit tool in supporting a more gender sensitive private sector through presenting the process, the challenges, and key learning. 


\section{O2 OXFAM'S APPROACH TO GENDER AUDIT}

Over the past three years, Oxfam has conducted 16 gender audits in the West Bank and the Gaza Strip on a diverse group of companies, cooperatives, and enterprises in the agriculture sector.

Building on the 2018 gender-sensitive pilots that mainly targeted working conditions, Oxfam's approach with these 16 companies followed several steps starting with company identification, and ending with follow-up as illustrated in the below diagram.
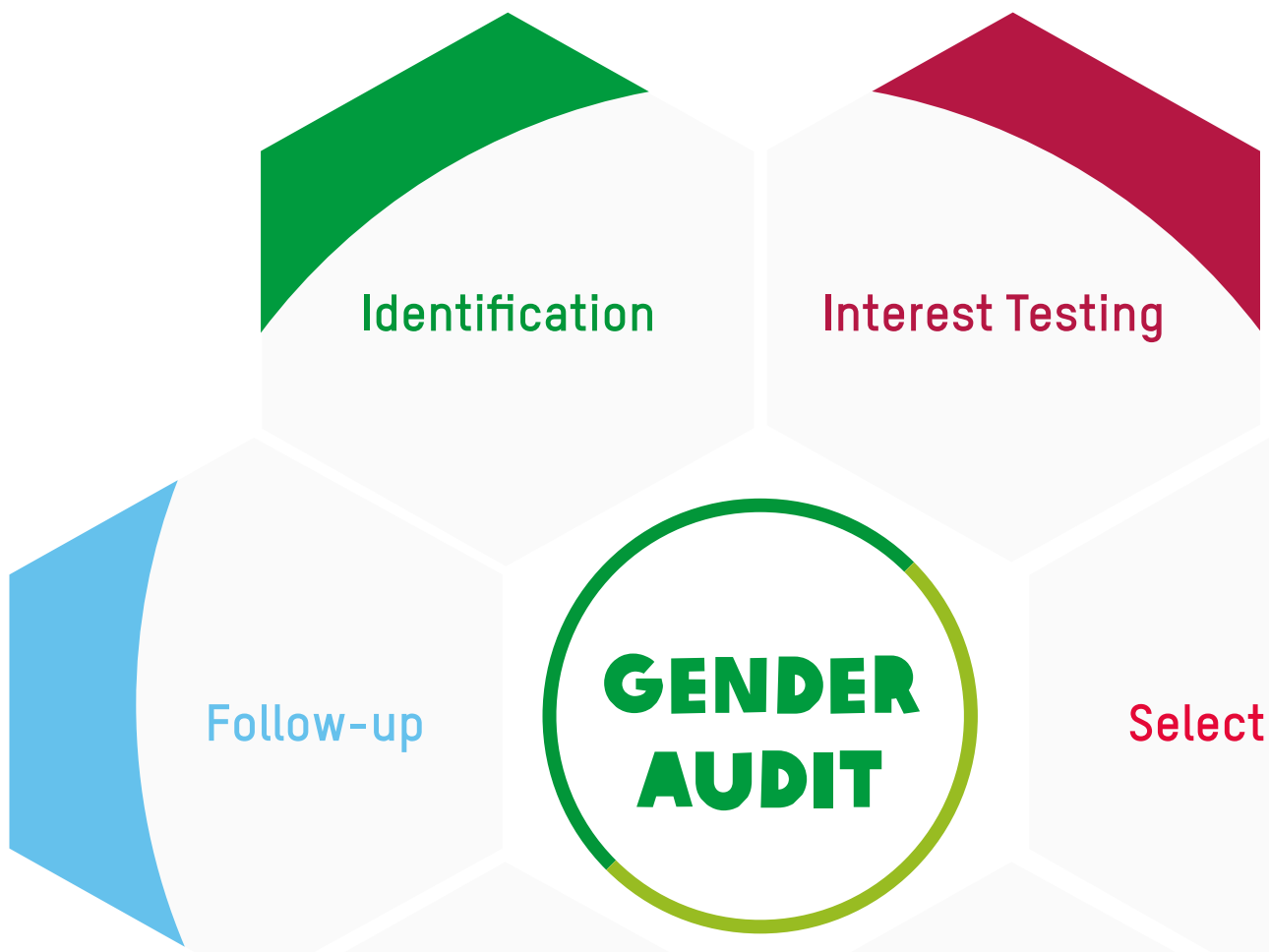

Selection
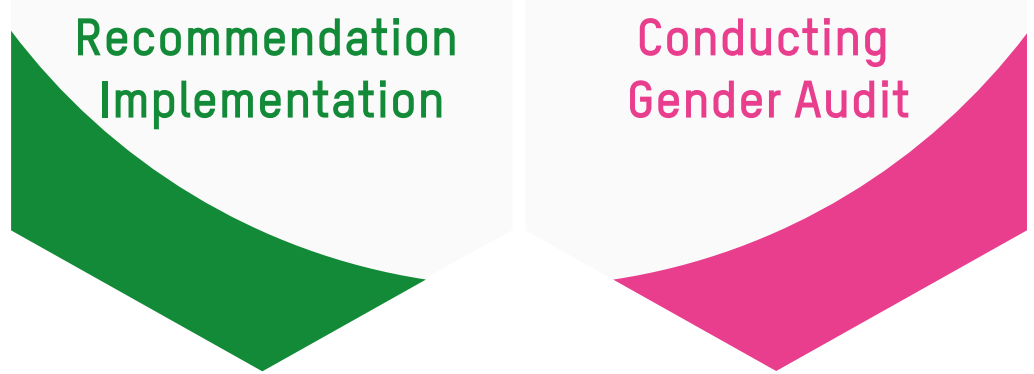


\section{Participatory Gender Audit Steps:}

1- Company identification: Oxfam engaged in discussions with partners and sector representatives to identify companies that might be interested in conducting the gender audit and/or have female workers within their labor force.

2- $\quad$ Testing the interest: This step involves visiting the management and owners of these companies and cooperatives to explain the concept of gender auditing and the business case associated. The aim of these visits is to assess the existence of interest, or lack thereof, in addition to the existence of political will and commitment by the management.

\section{3- Company selection and expectations setting: Once the company}

shows interest in conducting the gender audit, Oxfam communicates a brief about the gender audit in Arabic explaining the process, objectives, time and resources commitment, as well as the selection of a contact person within the company. At this stage, it is important to pay another visit to the board of directors, or company owners to answer any inquiries or clarify any uncertainties. This requires a full understanding and analysis of how a gender audit might affect the company's bottom line; which can be challenging within the Palestinian context. 
4- $\quad$ Conducting the gender audit process: An experienced gender auditor will start the process by having the company follow the ILO's tool in outlining the key areas of analysis, conducting a desk review, interviewing stakeholders at various managerial levels, workers, and lastly workshops. The ILO's approach is customized to better suit the circumstances of each individual company, particularly when determining areas of analysis which generally address management and governance, staffing and human resources, policies and procedures, awareness of and perception of gender equality, companies' activities, services, and products, and finally the work environment. Once the audit is conducted, it is shared with the respective companies for their feedback and approval.

5- Recommendations implementation: Once the results of the gender audit are approved, Oxfam with the company's management identifies priority areas of recommendations and the best way to implement them. An action plan is developed for implementing the agreed on recommendations with a clear time frame and budgets to be allocated for each recommendation.

6- Follow-up: To make sure real political will is in place, and to enhance the strategic relationship with the company, a follow-up mechanism must be implemented to assess the extent to which the recommendations have been implemented, and to assess any support that might be needed. 


\section{O3 KEY FINDINGS, CHALLENGES, AND LESSONS LEARNED}

This section discusses the main takeaways, key findings, and lessons learned throughout the process.

\% OF FEMALE REPRESENATION IN AUDITED COMPANIES
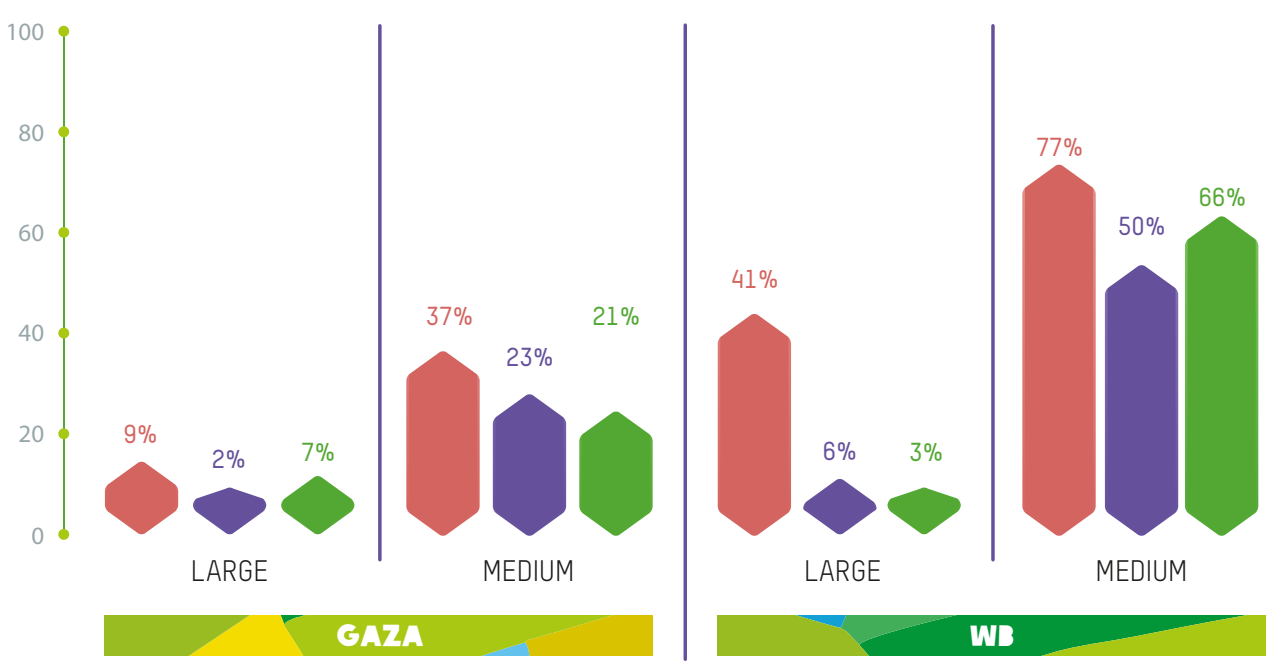

Average of $\%$ of female permenant workers

Average of $\%$ of female BoD

Average of $\%$ of female owners

\section{Main Findings:}

- Socio-economic impact: The Palestinian economy faces systematic suffocating challenges that have relegated economic growth and hindered private sector growth. The economic stagnation has not only deepened the chronic poverty issue, but also increased unemployment levels, particularly young women and men. The impact of this collapse is manifested in a high workforce supply with limited demand for labor. This pushes young women and men into accepting any job regardless of work conditions or low salaries. At the same time, small and medium private sector companies in agriculture are struggling to survive. This has resulted in high dependency on daily waged laborers, part-time jobs, and seasonal workers, with the majority having no formal contracts for their workers, who are usually paid below the Palestinian minimum wage. This is highly evident in the Gaza Strip. This pushes social responsibility to the bottom of the priority list of these companies, and hinders providing workers with decent work conditions leading to reluctance among workers in demanding their labor rights and making them hesitant to provide honest opinions for the gender audit. 
- Inadequate women representation in companies as owners, members in boards of directors, and high managerial positions. The average representation differs based on the geographical location, company size, and type as illustrated in the graph.

In the OPT, women make up less than $8 \%$ of the boards of directors and owners of large companies. Some audited companies attribute such a low percentage to these being "family businesses". However, there is a striking difference between audited companies in the Gaza Strip and those in the West Bank with regards to female workers in large companies. In the Gaza Strip, the concentration of large companies in the industrial zone renders them less accessible to females wishing to join the labor force.

There is a higher concentration of women at the lower levels in labor forces in the audited companies, usually secretarial and workers with no job security, contracts, or insurance, such as seasonal and daily waged workers. The companies' scope of work is a key factor determining the need for seasonal workers. This tendency is prominent at companies working in sorting and storing fresh and frozen vegetables and fruits. In the West Bank, women have high representation as owners, workers and board members, mainly in the case of medium-sized cooperatives which are usually women-led.

- This low representation also travels across the value chain, with the majority of audited companies reporting few to no female suppliers of agricultural raw materials, lacking in consideration with regards to gender disaggregation data for their suppliers or customers, and limited representation of women in their advertisement materials. One of the justifications provided was the necessity of dealing with large suppliers who are predominantly men, who are more able to meet the required quantities and quality of needed raw materials. 
- A majority of the companies had an organizational structure in place illustrating the various departments and managerial positions leading these departments. However, the existence of managerial, financial, and human resource manuals and complaints systems is highly dependent on the size and formalization of the businesses; with medium and formal businesses engaged in exports having some of these manuals, ISO certification, and investment in technical capacity building. The majority of West Bank's large and medium audited companies had HR manuals or policies, while only a few of Gaza's large companies did. Nonetheless, none of the companies had any gender mainstreaming or anti-harassment policies. The lack of gender-sensitive language in manuals, policies, structures, human resource procedures, and job advertisements was a prevalent theme across all audited companies regardless of their size, location, and type. This is highly associated with these companies' understanding of and commitment towards gender inclusion in their work.

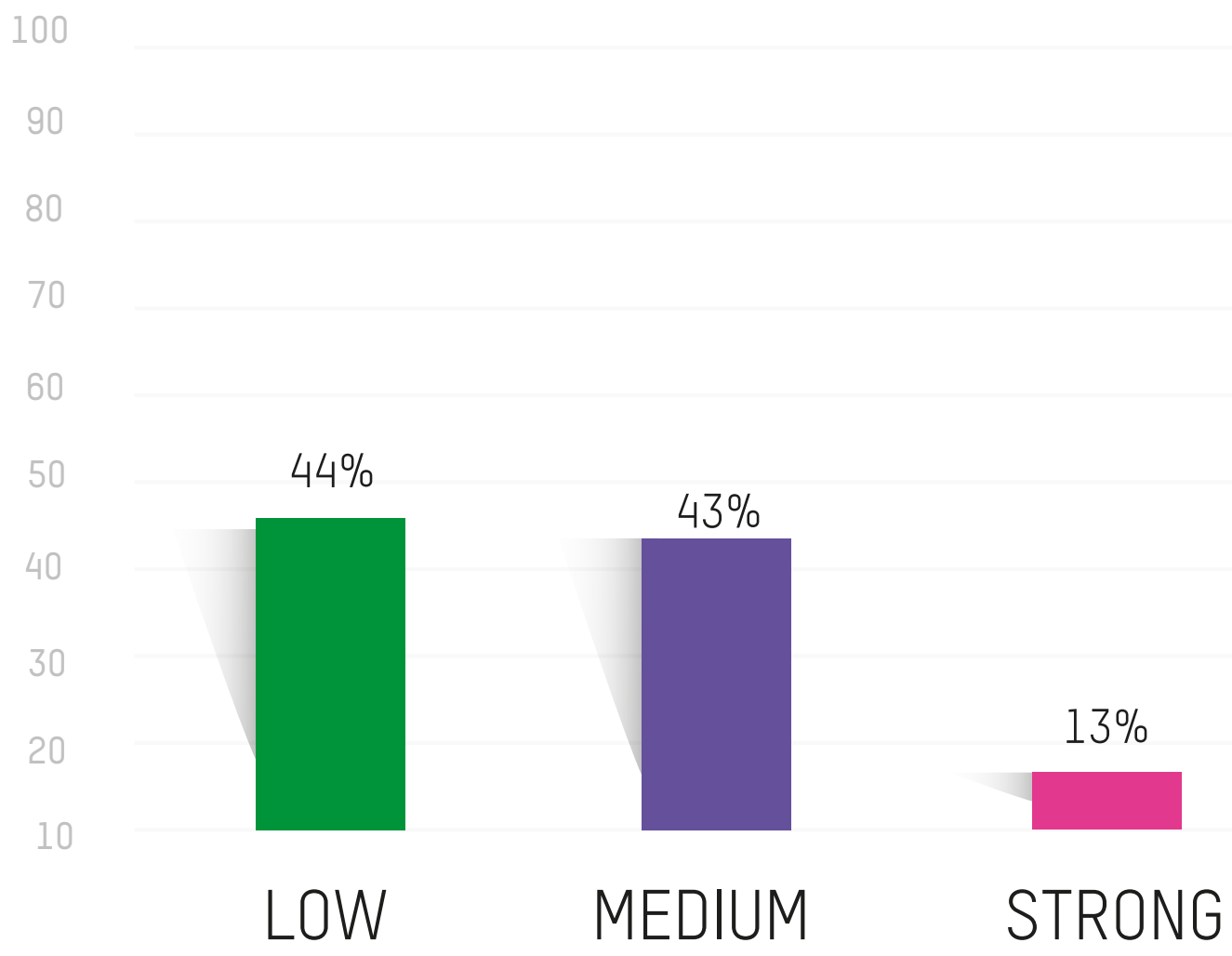


- The audited companies' compliance with labor laws ranged from weak to strong. For example, a majority of large companies provide breastfeeding hours and maternity leave but vary in their degree of compliance with the periods stated in the Labor Law. However, none of the companies, regardless of their size, provide parental leave for their male staff.

\section{- A limited understanding of gender concepts, women's rights} issues, and gender equality was prevalent among most companies. Neither staff nor management has ever had any kind of gender awareness training or discussions. Only 2 of the audited companies in the West Bank showed a strong understanding of gender terms and language which are instrumental in the application and adoption of the audit recommendations.

There was a clear difference between the West Bank and the Gaza Strip with regards to gender-sensitivity in the work environment. In the West Bank, audited companies did have proper facilities that accommodate both females and males, while the majority of companies in the Gaza Strip lacked a gender-sensitive work environment such as the allocation of sanitary amenities like toilets and changing rooms for women, and insufficient consideration for ergonomic hazards faced by both male and female workers due to prolonged static postures. For example, in companies sorting vegetables and fruits, women tend to sit on the ground while cleaning and sorting fruits such as dates which leads to chronic diseases in the long run. Some work environments expose workers to weather conditions, heat, and poor ventilation. Other companies are located in remote areas, which can be challenging for women to work in due to mobility and safety concerns and transportation costs.

- Regarding the audit recommendations implementation, the most prevalent trend in small and medium semi-formal businesses was to invest in gender-sensitive infrastructure with minimal attention to labor rights such as formal employment. On the other hand, institutional changes in company policies and capacity building for staff were a more common response among medium and formal businesses. 


\section{Challenges:}

- The Participatory Gender Audit and gender equality is a new concept to the agricultural and food processing sector. This causes a lack of understanding of its business case which results in high reluctance to participate in the audit or implement its recommendations.

The gender audit analysis involves reading documents and inquiring about the work environment, workers and employees' salaries, ranks and rights. Given the high economic volatility, some private sector companies' compliance with the Labor Law is insufficient. This instigates fear or reluctance with regards to sharing information about work conditions and workers rights such as salaries, the existence of formal contracts, working hours, compensation for overtime work, etc.

- The number of experienced and certified gender auditors across the OPT is limited in general, and particularly in the Gaza Strip where there are none.

- The Participatory Gender Audit tool is better suited for large companies and organizations that have a strong institutionalization and documentation system with clear policies and structures. Therefore, the tool required adjustment to make it more suitable and user-friendly with an emphasis on a simplified language. This, coupled with the relatively high cost of conducting a gender audit by a certified auditor given the size and nature of the targeted companies, negatively affect the feasibility of conducting the gender audit. 
- There is limited knowledge on the part of management and employees in areas of gender concepts and gender equality, particularly as traditional patriarchal perceptions are unconsciously mirrored in how these companies function. This requires more effort to explain, discuss and persuade the companies of the added value of mainstreaming gender equality to their work.

- The spread of coronavirus during the implementation of the gender audits conducted this year has delayed conducting face-to-face interviews and field visits particularly with the workers.

- Some companies in the Gaza Strip are operating out of temporary locations as their original locations and infrastructure were destroyed during the different escalations in the past decade. This creates hurdles in the face of efforts to implement the recommendations for improving the work environment. 


\section{Lessons learned:}

1. The political will of the company's top management is crucial not only to ensure the success of the audit, but also for the implementation of the recommendations for the gaps identified.

2. Depending on the size and nature of the business (formal, semi-formal, or informal), an adaptation of the gender audit tool has to be made to its pillars, research methodology, and recommendations.

3. The importance of having governmental laws incentivizing the private sector to become more gender-sensitive.

4. It is very important to use business-friendly language, utilizing the "commercial rationale" of women's inclusion in business as workers, decision makers, and consumers. This will help encourage private sector businesses to undertake a gender audit once they see the impact on their bottom line.

5. In collapsing economies where the private sector is struggling, a gender audit and inclusion measures are more successful if run in parallel with economic development interventions depending on the business size. For example, we found that large companies were motivated by leveraging their image and reputation among their stakeholders and customers, while small companies are more interested in infrastructure modification towards a better work environment for workers.

6. Using business friendly and added value-driven language instead of gender terms when communicating with companies is key to drive political will and commitment.

7. Raising awareness and engaging with staff in discussions about gender terms, issues, and their applications in business and on the community is a vital step towards achieving willingness for participation and engagement.

8. Setting expectations and levels of involvement at the beginning of the gender audit by each party is key to the acceptance and adoption of gender audit recommendations. 


\section{STEPS TOWARDS CHANGE}

The Khan Younis Agricultural Cooperative Society in the Gaza Strip amended its membership conditions to be more sensitive to the socio-economic factors hindering women's participation. Hence, it endorsed four alternative ways that can provide for women's ownership of land instead of the formal registry. These include: the formal ownership/inheritance registry deed, inheritance document proving the father/mother's land ownership, endorsement from the Mukhtar (tribal and local leader), or an endorsement by two board members of the cooperative. Furthermore, during their election that took place in 2020, two female members were elected to the board of directors. Similarly, the Kafr Dan Pickles Factory in the West Bank hired two female members as part of the senior management for the factory.

Al Radwan Company in the Gaza Strip has made changes in their shareholders' composition and included three women investors as additional owners in the company. One of these female owners is responsible for the management of the company. Furthermore, the company co-invested in improving the work conditions and infrastructure to be more gender-sensitive. Mazaj Company, on the other hand, committed to strategically increase the percentage of their company's female suppliers from 2 percent to 5 percent by 2023. In the West Bank, Al Hijaz Company invested in the rehabilitation of their production site to make it safer and more sensitive to women's needs. Haifa Company showed commitment towards equal pay for female and male workers doing the same job. 


\section{NOTES}

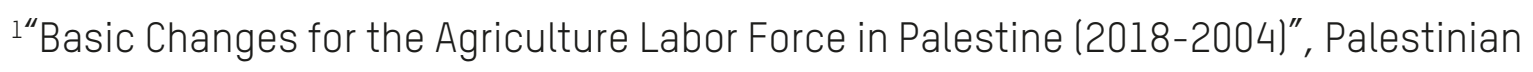
Central Bureau of Statistics, 2019. PCBS website, labour time series.

$2^{2 \prime}$ Percentage Distribution of Employed Individuals Aged 15 Years and Above in Agriculture, Hunting $\delta$ Fishing Activity in Palestine by Region, Employment Status and Sex, 2018", Palestinian Central Bureau of Statistics, 2019. PCBS website, labour Force Survey Database, 2018.

30xfam unpublished study (2016). "Making Agricultural Markets Better Work for Women in the Occupied Palestinian Territory."

4"A manual for Gender Audit Facilitators". The ILO participatory gender audit methodology, 2nd Edition, 2012. 


\section{ACKNOWLEDGEMENTS}

This learning paper was prepared by Asmaa AbuMezied, Women's Economic Empowerment Coordinator in Oxfam OPTI-Gaza office, and Rahhal Rahhal, Women's Economic Empowerment Coordinator in Oxfam OPTI-West Bank office. It was conducted as part of a collaborative project under the Economic Justice portfolio in OPT that supports smallholder farmers in different value chains across OPT. Oxfam is grateful to the companies, cooperatives, communities, women and men, and the different stakeholders for their generosity in providing their perceptions, opinions, experiences and expertise in the area of mainstreaming gender equity in the private sector.

The paper was made possible under the activities of the "Integrated Market Development Program across the occupied Palestinian Territory" through joint funding from the Ministry of Foreign Affairs of Denmark/International Development Cooperation (DANIDA) and the Swiss Agency for Development and Cooperation (SDC). 


\section{Oxfam Research Reports}

Oxfam Research Reports are written to share research results, to contribute to public debate and to invite feedback on development and humanitarian policy and practice. They do not necessarily reflect Oxfam policy positions. The views expressed are those of the author and not necessarily those of Oxfam.

\section{(C) Oxfam International April 2021}

This case study was written by Asmaa AbuMezied and Rahhal Rahhal. It is part of a series of papers and reports written to inform public debate on development and humanitarian policy issues.

For further information on the issues raised in this paper please email Luay Alwuhaidi, luay.alwuhaididoxfam.org

This publication is copyright but the text may be used free of charge for the purposes of advocacy, campaigning, education, and research, provided that the source is acknowledged in full. The copyright holder requests that all such use be registered with them for impact assessment purposes. For copying in any other circumstances, or for re-use in other publications, or for translation or adaptation, permission must be secured and a fee may be charged. Email policyandpractice@oxfam.org.uk. The information in this publication is correct at the time of going to press.

Published by Oxfam GB for Oxfam International under ISBN 978-1-78748-7338 in April 2021.

DOI: $10.21201 / 2021.7338$

Oxfam GB, Oxfam House, John Smith Drive, Cowley, Oxford, OX2 4JY, UK. 
